\title{
Desafios na psicoterapia online: reflexões a partir de um relato de caso de uma paciente com ansiedade
}

\section{Challenges in the online psychotherapy: reflections from a case report of a patient with anxiety}

\section{Desafíos en psicoterapia online: reflexiones de un informe de caso de un paciente con ansiedad}

\author{
Gustavo Assi ${ }^{1}$, André Luiz Thieme ${ }^{2}$
}

[1] [2] Unifebe-Brusque, SC, Brasil I Título abreviado: Desafios na Psicoterapia Online I Endereço para correspondência: CEP 88356.011, (47) 9 9171-8918 | Email: gustavoassi@unifebe.edu.br I doi: 10.18761/PAC.2019.v10.n2.06

Resumo: Observa-se uma crescente demanda por serviços psicológicos online, como o uso para intervenções por programas computadorizados de terapia e de psicoterapia pela internet. Este artigo busca avaliar o estabelecimento do vínculo terapêutico online, na abordagem da Análise Clínica do Comportamento, considerando o caso de um cliente que apresenta comportamentos de fuga e esquiva em situações sociais. O recrutamento foi realizado a partir de prontuários na Clínica Escola e Serviços em Psicologia (CESP), por indivíduos, acima de 18 anos, que satisfizessem os critérios e pela divulgação da pesquisa em meios oficiais e redes sociais. Duas pessoas foram escolhidas. Foram realizadas duas sessões com uma paciente de 38 anos, nas quais ocorreram um total de nove travamentos, quatro quedas de conexão e três faltas, uma das sessões interrompida pela má qualidade de conexão. A paciente de 23 anos não participou devidos problemas técnicos. Os resultados encontrados demonstram que a presença de familiares no mesmo recinto em que a paciente se encontra durante os atendimentos online podem prejudicar o andamento da psicoterapia. Os elementos diferenciados de atendimentos online podem ser utilizados com recurso de fuga e esquiva. Por fim, nas condições apresentadas, não se pôde verificar a eficácia do atendimento psicoterapêutico online, fazendo-se necessário mais estudos.

Palavras-chave: Psicoterapia online, clínica analítico-comportamental, audiência não punitiva, vínculo terapêutico.

Os autores supracitados declaram ter respeitado todas as aplicações éticas necessárias, bem como o termo de consentimento livre e esclarecido, tendo o trabalho sido aprovado pelo comitê de ética sob o número 73396917.0.0000.5636. Do mesmo modo, os autores supracitados também declaram não terem conflitos de interesse de ordem financeira, comercial, política, acadêmica e pessoal.

Agradecimentos

O presente artigo foi produto do trabalho de conclusão de curso (TCC). Agradeço ao meu orientador André Luiz Thieme pelas horas de partilha de conhecimento. Correspondência referente a este artigo deve ser enviada para psigustavoassi@hotmail.com. 


\begin{abstract}
There is a current growth on the search for online psychological services, such as interventions by computerized therapy and even online psychotherapy. This article evaluates the therapeutic link built on an online care using Applied Behavior Analysis for people who present escape and avoidance behaviors in social situations. Records at CESP were read for recruiting individuals over 18 years old that met the criteria. The research was published on institutional media and social networks. Two people were chosen, one by the CESP record. Two sessions were performed with the 38-year-old patient, occurring a total of nine blockages and four drop-outs and three missed appointments, and one session interrupted by poor connection quality. The 23 years old patient had a notebook failure, she didn't continue in the study. Presence of family members in the same room where the patient is during online therapy may jeopardize the progress of psychotherapy. Special characteristics of online counseling may be used as resources for escape and avoidance behavior. Finally, under the conditions met, it was not possible to verify the efficacy of online psychotherapeutic care, making further study on the topic necessary.
\end{abstract}

Keywords: Online psychotherapy, applied behavior analysis, non-punitive audience, therapeutic alliance.

Resumen: Se observa una creciente demanda por servicios psicológicos en línea, como el uso para intervenciones por programas computarizados de terapia y de psicoterapia por Internet. Este artículo busca evaluar el establecimiento del vínculo terapéutico online, en el abordaje del Análisis Clínico del Comportamiento, en una persona que presenta comportamientos de fuga y esquiva en situaciones sociales. El reclutamiento fue realizado a partir de prontuarios en la Clínica Escuela y Servicios en Psicología (CESP), por individuos, mayores de 18 años, que satisfagan los criterios y la divulgación de la investigación en medios oficiales y redes sociales. Se realizaron dos sesiones con una paciente de 38 años, en la que ocurrió un total de nueve bloqueos, cuatro caídas de conexión y tres faltas, una de las sesiones interrumpida por la mala calidad de conexión. La paciente de 23 años no participó en problemas técnicos. Los resultados encontrados demuestran que la presencia de familiares en el mismo recinto puede perjudicar el progreso de la psicoterapia. Los elementos diferenciados de los servicios en línea se pueden usar con escape y evasión. Por último, en las condiciones presentadas, no se pudo verificar la eficacia de la atención psicoterapéutica online, haciéndose necesario más estudios.

Palabras clave: Psicoterapia en línea, clínica analítica-conductual, audiencia no punitiva, vínculo terapéutico. 
Segundo o Instituto Brasileiro de Geografia e Estatística (IBGE), o número de domicílios com acesso à internet passou de 54,9\% em 2014, equivalente a 36,8 milhões de domicílios, para 57,8\% em 2015 , o que equivale a 39,3 milhões de domicílios (IBGE, 2015). Os motivadores para os acessos à internet são variados, vão desde a busca de acesso à comunicação à busca de prestadores de serviços variados, incluindo a busca por serviços em saúde (Rodrigues \& Tavares, 2016).

Do mesmo modo, observa-se uma crescente busca por serviços psicológicos online, como o uso para intervenções por programas computadorizados de terapia e, inclusive, de psicoterapia pela internet, por meio de e-mail, chat, áudio ou videoconferência, não excluindo a possibilidade de encontros presenciais (Pieta \& Gomes, 2014). No dia 14 de Novembro entrou em vigor a resolução CFP no $11 / 2018$, o qual atualiza a resolução CFP n ${ }^{\circ}$ $11 / 2012$, não mais limitando o número de sessões e derrubando a restrição do atendimento psicoterapêutico online como apenas em caráter experimental (CFP, 2018).

A psicoterapia pela internet vem se estabelecendo como uma forma de realizar atendimentos a distância, tanto pela sua disponibilidade e conveniência, como também pelo baixo custo, anonimato, privacidade e redução de estigma (Pieta, Siegmund, Gomes \& Gauer, 2015). Entretanto, até então, poucos estudos foram realizados para se comprovar a eficácia do tratamento psicológico via internet (Pieta et al. 2015), estudos esses necessários para compreensão da prática, conforme apontava a resolução $n^{\circ}$ 011/2012 do CFP (CFP, 2012). Mesmo com a nova resolução, vale lembrar que a prática acabou de ser regulamentada e novos desafios se aproximam.

Conforme Pieta e Gomes (2014), o atendimento psicoterápico online demonstra-se um fazer promissor no tratamento da depressão, ansiedade, fobia, transtorno de pânico, transtornos alimentares e estresse pós-traumático. Do mesmo modo, a psicoterapia online pode ser utilizada também com crianças e adolescentes, em que o anonimato e o sentir-se seguro podem ser fatores auxiliares no tratamento de pessoas com diagnóstico de transtornos ansiosos, como agorafobia e fobia social (Pieta \& Gomes, 2014).
Partindo da premissa que a psicoterapia online provê ao indivíduo anonimato e um sentimento de segurança quanto a autorrevelação, o presente estudo realizou atendimento psicoterapêutico online na abordagem da Análise do Comportamento, no qual foram focados casos com características de transtornos ansiosos, como agorafobia, fobia social e pânico. Conforme apresentado, o atendimento psicoterapêutico não impossibilita a relação entre cliente e terapeuta, sendo inclusive uma ferramenta valiosa em casos que apresentem características de transtornos ansiosos, em casos em que o cliente prefira um terapeuta de outra cidade, em situações de mudança de cidade ou viagem por parte do terapeuta ou cliente.

\section{Atendimento Psicoterapêutico online}

A busca por prestadores de serviços variados, desde a crescente expansão da internet no Brasil, tem aumentado (IBGE, 2015). Nessa via, aumentou a procura por serviços de saúde disponibilizados na internet, dentre eles, atendimentos psicológicos como a psicoterapia online, realização de testes, questionários, entre outros (Rodrigues \& Tavares, 2016).

A utilização de intervenções baseadas na internet, bem como a própria psicoterapia online, tenham se demonstrado viáveis para o tratamento da depressão, ansiedade, fobia, transtorno de pânico, transtorno obsessivo-compulsivo, estresse pós-traumático e transtornos alimentares (Pieta \& Gomes, 2014; Siegmund, Nonohay \& Gauer, 2016; Pieta et al. 2015). Porém, sua aceitação recebeu grande oposição. Acreditava-se que a relação terapêutica seria prejudicada pelo empobrecimento da comunicação não verbal, que questões éticas acerca da confidencialidade dos atendimentos não seriam atendidas e que o manejo de situações de emergência seria igualmente prejudicado, entretanto as desconfianças diminuíram com as tentativas bemsucedidas (Pieta \& Gomes, 2014).

Resultados obtidos em pesquisas apontam que a desinibição e a sensação de liberdade para falar de si na psicoterapia online, sem constrangimento ou julgamento, são vantagens desse serviço (Rodrigues \& Tavares, 2016). O anonimato apresentado em 
comunicações assíncronas podem favorecer pessoas com dificuldade para realizar psicoterapia, enquanto a comunicação síncrona com câmera de vídeo pode reduzir o desconforto de indivíduos que apresentam timidez (Rodrigues \& Tavares, 2016).

Um projeto de pesquisa de cunho psicanalítico pensado por Donnamaria e Terzis (2011), no qual participaram dez pessoas, buscou estabelecer as primeiras considerações de manejo e desafios éticos em terapia de grupo via internet. Em outro artigo, objetivando avaliar os principais aspectos de usabilidade de uma intervenção psicoeducacional computadorizada sobre TOC em 21 pessoas da população em geral, Siegmund et al. (2016) concluíram que este tipo de intervenção poderia proporcionar benefícios para profissionais e usuários. Do mesmo modo, pela fácil disseminação na rede, contribuiria para o aumento do conhecimento da população sobre saúde mental, psicopatologia e tratamentos disponíveis.

Faz-se necessário, antes de discutir o conceito de psicoterapia online, a distinção entre intervenções baseadas na internet e psicoterapia online. As intervenções baseadas na internet são constituídas por programas computadorizados, nos quais pode ou não haver a participação do terapeuta, que incluem a utilização de softwares, CDs, DVDs, realidade virtual, aplicativos de smartphones, tarefas e feedback online. Esses programas são oferecidos por profissionais da saúde ou oferecidos em websites, objetivando auxiliar no tratamento e prevenção de transtornos mentais e recaídas (Pieta \& Gomes, 2014; Pinto, 2002; Pieta et al. 2015; Siegmund et al. 2016).

As intervenções baseadas na internet podem ainda incluir material informativo sobre a saúde mental em fóruns moderados e outros dispositivos na internet. Como exemplo, uma intervenção incluiria textos e gráficos para transmitir informação, vídeo apresentando conteúdo informativo, áudios para relaxamento progressivo, envio automático de e-mail e lembretes SMS, entre outros (Pieta \& Gomes, 2014). Esse tipo de intervenção é caracterizada por uma conexão assíncrona, realizada via e-mails e fóruns, em que emissor e receptor não estejam conectados ao mesmo tempo. Entretanto, a comunicação assíncrona deve ser evitada com clientes que demandem uma maior atenção, como indivíduos com distúrbios psicóticos e clientes que apresentem alto grau de ansiedade e angústia, onde uma intervenção com comunicação síncrona seria o mais recomendado (Rodrigues \& Tavares, 2016).

A comunicação síncrona diz respeito à intervenção entre pessoas conectadas simultaneamente, em tempo real, seja por meio de chat, mensagens instantâneas ou conversas com vídeo e voz e videoconferências. Do mesmo modo que uma psicoterapia, esse tipo de comunicação é realizada pelo menos uma vez por semana (Rodrigues \& Tavares, 2016). A psicoterapia online se refere mais precisamente às terapias disponibilizadas por profissionais via programas de mensagem instantânea, chat, áudio ou videoconferência, sem excluir a possibilidade de se realizar encontros presenciais (Pieta \& Gomes, 2014). Do mesmo modo, a psicoterapia online não se estabelece como uma nova modalidade de psicoterapia, mas sim como um novo meio de realizá-la, na qual o terapeuta se encontra em lugar diferente do qual o cliente está, mas, ainda assim, estabelecendo o vínculo terapêutico (Marot \& Ferreira, 2008).

O vínculo terapêutico, na perspectiva da Análise do Comportamento, se dá pelo estabelecimento da audiência não punitiva por parte do terapeuta; este não critica, não julga e não aponta erros no cliente (Skinner, 2003; Meyer, Oshiro, Donadone, Mayer \& Starling, 2008; Santos, Santos \& Marchezini-Cunha, 2012b). No atendimento psicoterapêutico online pesquisas mostram que, diferentemente do que se imaginava, a relação terapêutica não é prejudicada, apresentando inclusive semelhanças entre ambas modalidades, presencial e online (Pieta \& Gomes, 2014).

\section{A relação terapêutica na Análise do Comportamento}

A relação terapêutica ganhou relevância quando foi evidenciado que esta facilitava mudanças clínicas relevantes. Desse modo, estudos que buscavam identificar comportamentos do terapeuta e características das interações em clínica começaram a serem feitos e, atualmente, discute-se que esta relação é essencial para a adesão e sucesso do tratamento (Peron \& Lubi, 2012). 
Uma relação é constituída por um conjunto de interações entre indivíduos, interações que são permeadas por reforço mútuo, nas quais cada pessoa provê reforço para os comportamentos da outra (Baum, 2006). Em ambiente clínico, a relação que é estabelecida é a relação terapêutica, geralmente composta pela díade terapeuta e cliente. Diferente de outras relações, a relação terapêutica retém um caráter de ajuda (Alves \& Isidro-Marinho, 2010).

O comportamento verbal, que predomina durante as interações no ambiente clínico (Hamilton, 1988 citado por Medeiros, 2002), é caracterizado como operante, pois altera o ambiente na medida em que é alterado pelas consequências ambientais por ele suscitado (Barros, 2003). Comumente, nessas interações clínicas, o cliente irá relatar acontecimentos passados, presentes, o que provavelmente acontecerá ou ainda relatar sentimentos, emitindo assim o operante verbal tato (Santos et al., 2012b). Esse operante é controlado por estímulos discriminativos antecedentes, como eventos ou objetos, e amplia o contato do terapeuta com o mundo do cliente (Santos, Santos \& Marchezini-Cunha, 2012a).

O operante verbal tato é, também mantido por consequências reforçadoras. Esse operante, por sua vez, têm maior probabilidade de emissão na presença de um ouvinte, considerado uma audiência. A audiência tem a função de um estímulo discriminativo, pois sinaliza a disponibilidade de reforço por parte do ouvinte, controlando a força ou probabilidade de emissão de respostas e de topografias específicas de tato (Skinner, 1957 citado por Moreira \& Hanna, 2012).

Durante o processo terapêutico, faz-se necessário que o terapeuta assuma uma posição diferente àquela esperada em outros contextos. Gradualmente estabelecendo-se como uma audiência não punitiva, o terapeuta estabelece um ambiente no qual comportamentos até então punidos podem ser emitidos e, como consequência, alguns resultados da punição poderão enfraquecer. Desse modo, a audiência não punitiva surge como uma ferramenta para que se crie o vínculo entre terapeuta e cliente (Medeiros, 2002; Skinner, 2003; Vandenberghe \& Pereira, 2005; Santos et al., 2012b).

O desenvolvimento de uma relação terapêutica positiva pode facilitar o fornecimento de informações na terapia. $\mathrm{O}$ estabelecimento desta rela- ção pode levar a um maior engajamento do cliente na terapia, promovendo expectativas positivas e superação de resistências, visto que o cliente se sente confortável para fornecer informações clinicamente relevantes (Prado \& Meyer, 2004). O cliente procura, aos poucos iniciar com revelações pouco punidas socialmente, evoluindo o relato para aquelas mais punidas socialmente, à medida que as revelações iniciais não são punidas pelo terapeuta (Santos et al., 2012b).

A relação terapêutica se dá quando são consideradas as qualidades pessoais do terapeuta, do cliente e das interações que ocorrem em ambiente clínico. A qualidade da relação terapêutica estabelecida determinará a eficiência do processo terapêutico. Desse modo, o terapeuta deve sempre buscar estabelecer um bom vínculo com seu cliente, possibilitando um ambiente confortável e acolhedor para que ele possa falar o que e como quiser. Partindo da lógica de que os comportamentos-alvo originados fora da terapia tendem a ocorrer em ambiente clínico, o terapeuta poderia utilizar suas próprias reações de modo a modelar os comportamentos do cliente, fazendo uso de reforçadores naturais (Alves \& Isidro-Marinho, 2010).

Toda resposta é mantida por reforço, seja ele positivo ou negativo. Indivíduos que tenham sido expostos a contingências sociais aversivas, quando não conhecem formas alternativas de se comportar, tendem a apresentar respostas de fuga e esquiva (Rocha, 2012). No caso de respostas de fuga e esquiva, ocorre o reforçamento negativo, que é a apresentação, como consequência, da redução ou cessamento de estímulos aversivos (Skinner, 2006). Funcionalmente, respostas de fuga e esquiva dificultam a exposição do indivíduo a novas contingências de reforçamento, a emissão de novos comportamentos operantes reforçados positivamente é prejudicada (Rocha, 2012).

Quando um estímulo precede a ocorrência de um estímulo aversivo, pode-se observar a ocorrência de respostas geralmente denominadas de ansiedade (Skinner, 2006). De modo geral, a ansiedade é sentida em uma situação que um estímulo condicionado sinaliza a presença de um estímulo aversivo. Esse estímulo condicionado pode eliciar uma série de respostas emocionais e evocar respostas operantes, que serão reforçadas caso 
haja remoção, ou diminuição, da possibilidade de ocorrência do estímulo aversivo (Rico, Golfeto \& Hamasaki, 2012).

Quando o indivíduo com características ansiosas emite a resposta de ficar em casa, sua resposta de esquiva é negativamente reforçada, ocasionando um aumento na frequência desse comportamento. Desse modo, quando a esquiva é bem-sucedida, a pessoa é impedida de entrar em contato com contingências positivamente reforçadoras. Em casos assim, um dos objetivos da terapia é expor gradualmente o cliente à essas contingências, visando o desenvolvimento de habilidades sociais (Fugioka \& de-Farias, 2010).

O anonimato proporcionado pelo atendimento online pode auxiliar pessoas introvertidas, com transtorno de ansiedade, como agorafobia e fobia social, a procurarem ajuda profissional (Pieta \& Gomes, 2014). Desse modo, partindo do pressuposto de que a psicoterapia online poderia auxiliar no tratamento de pessoas com diagnóstico de transtornos ansiosos, como agorafobia e fobia social (Pieta \& Gomes, 2014), a psicoterapia online poderia ser uma ferramenta para o clínico analítico-comportamental no tratamento de transtornos ansiosos, uma vez que esta possa ser um primeiro contato para o desenvolvimento de habilidades sociais e exposição gradual à outras contingências, incluindo a psicoterapia presencial.

\section{Método}

\section{Participantes}

O recrutamento foi realizado por meio de levantamento das fichas de acolhimento na Clínica Escola de Serviços de Psicologia (CESP), além da divulgação do projeto de pesquisa em canais de comunicação oficiais e redes sociais, com indivíduos acima de 18 anos que apresentassem queixas relacionadas à ansiedade. Após a análise de 28 prontuários e de 1 retorno por meio da divulgação da pesquisa nos canais de comunicação elegidos, somente duas participantes foram selecionadas, uma por meio de prontuários, sendo uma mulher de 38 anos, e a indicação pelos canais de comunicação, sendo uma mulher de 23 anos. Os convites foram realizados via telefone e aplicativos de mensagem instantânea.
A primeira sessão foi realizada presencialmente e teve o objetivo de levantar informações adicionais sobre os sujeitos de pesquisa, bem como explicar o funcionamento das sessões, como seriam realizados os atendimentos online, apresentar as ferramentas necessárias para a realização e verificar a aceitabilidade do sujeito em participar da pesquisa. Nesta sessão também foram apresentados os riscos e benefícios da pesquisa, bem como os direitos de cada participante por meio do Termo de Consentimento Livre e Esclarecido. Esta pesquisa respeitou os critérios éticos segundo a resolução 466/2012 e teve aprovação do comitê de ética sob parecer 2.276.324.

\section{Procedimento}

$\mathrm{O}$ acadêmico-pesquisador realizou os atendimentos a partir da CESP, por meio de um notebook de uso pessoal, no qual as sessões online foram mediadas por meio do software Skype, com ligações de áudio e vídeo. As sessões foram gravadas em áudio e vídeo utilizando-se do software Open Broadcaster Software (OBS), capturando a tela do pesquisador na qual apareciam o rosto da paciente e, em um quadro menor no canto inferior esquerdo, o acadêmicopesquisador. Os vídeos foram salvos em HD externo e em pastas com senha. As falas e expressões faciais das participantes foram transcritas, por meio de registro cursivo contínuo, utilizando linguagem científica, realizando-se a Análise Funcional destas ao longo das sessões. $\mathrm{Na}$ análise funcional, os comportamentos verbais e os não verbais foram identificados por meio de consequências de reforço negativo que poderiam indicar fuga ou esquiva em diferentes situações clínicas. Observando reações do terapeuta como antecedentes e consequências das respostas da participante. Também foram registrados momentos de corte e quedas de conexão, desvio da câmera do rosto da participante como possíveis respostas de fuga ou esquiva.

\section{Resultados e Discussão}

Das participantes da pesquisa, uma apresentou problemas com seu notebook, impossibilitando a continuação dos atendimentos online, porém foi dado continuidade ao atendimento de modo 
presencial. No âmbito deste artigo, o qual busca a avaliar a eficácia do atendimento psicoterapêutico online em indivíduos que apresentam comportamentos de fuga e esquiva em situações sociais, será apenas relatado e analisado os atendimentos online.

A paciente, mulher, 38 anos, casada e mãe de uma menina de nove anos, foi selecionada a partir dos prontuários da CESP, no qual o relato do seu acolhimento apresentava queixa de ansiedade social. Foi realizado um total de dois atendimentos online por videoconferência, sendo que o pesquisador-acadêmico o realizou em uma internet de 65 mbps às 21 horas. Durante a realização dos atendimentos houve diversas interferências tecnológicas e dificuldades da paciente no manuseio da tecnologia, sendo que um atendimento teve de ser interrompido por conta da conexão. A paciente, cujo atendimento foi realizado por videoconferência em um cômodo de seu apartamento, apresentou dificuldade para a instalação do software Skype em seu notebook e, desse modo, a sessão foi realizada com seu celular. Outra dificuldade encontrada foi o fato de a paciente ter logado no Skype com um login diferente, o que ocasionou a criação de outra conta, atrasando o início da segunda sessão.

Durante a realização da primeira sessão, houve um total de nove travamentos de conexão, totalizando 3'19" sem contato com a paciente, e quatro quedas de conexão, totalizando 1'28" sem contato com a paciente. $\mathrm{Na}$ segunda sessão, além da baixa velocidade da internet, a paciente apresentou dificuldades para logar em sua conta, atrasando o início do atendimento em 23'38”. A conexão foi estabelecida na terceira tentativa de chamada de vídeo, ocorrendo uma queda aos 34". A chamada foi estabelecida novamente na quarta tentativa, entretanto teve de ser interrompida, com o consentimento da paciente, aos 3'14" pelos constantes travamentos e cortes de áudio.

Ressalta-se ainda que houve um total de três faltas da paciente à terapia, entre a primeira e segunda sessão. A primeira falta ocorreu pelo fato da paciente não ter avisado com antecedência que tinha um agendamento para pintar os cabelos. A segunda ocorreu porque a paciente esqueceu o celular no seu trabalho, impossibilitando o atendimento. O terceiro deu-se pelo motivo da paciente ter solicitado um atraso da sessão no corrente dia, o que seria impossível devido ao seu horário usual ser o último do dia, além de ter solicitado que os atendimentos fossem realizados presencialmente.

Segundo Colombini e Pergher (2009) as faltas e atrasos comumente são interpretados como esquiva das sessões, ou mais precisamente, a esquiva de falar sobre algum assunto considerado aversivo. Do mesmo modo, travamentos, quedas de conexão e a possibilidade da paciente cobrir a câmera, abaixar a tela do notebook ou encerrar a chamada poderiam vir a contribuir para a esquiva e fuga de entrar em contato com os sentimentos aversivos. A dificuldade da paciente em lidar com tecnologia pode também representar um analfabetismo tecnológico. Segundo Melo (2016), esse tipo de analfabetismo refere-se a uma não capacidade em "ler" o mundo digital e utilizar tecnologia moderna, principalmente no que diz respeito aos domínios dos conteúdos sobre informática, sendo que a causa desse tipo de analfabetismo é associada à exclusão digital.

Um total de dez travamentos e quedas de conexão ocorreram em momentos críticos do atendimento (choro, soluços, fungadas, passar a mão no nariz, voz amarrada, assuntos delicados), dificultando a retomada do assunto, o que pode indicar esquiva. Outro fator que contribuiu para a dificuldade de entrar em contato com assuntos delicados, foi a presença de sua filha e de seu marido no apartamento onde a paciente estava, conforme explicitado abaixo:

J: Bastante complicado. Ah, eu não sei devo falar, é estranho * risos*

T: Não tem problema. Se tu não se sentir muito confortável falar agora, a gente pode chegar nesse assunto algum outro momento.

$\mathrm{J}$ : Aham. É estranho conversar assim ${ }^{\star} \mathrm{Ri}$ enquanto fala, passa a mão esquerda abaixo do nariz

T: É estranho? ${ }^{*}$ sorrindo*

J: É estranho * ${ }^{*}$ sorrindo*

T: Tu não se sente confortável falando dessa maneira?

$\mathrm{J}:{ }^{*}$ mexe a cabeça de um lado a outro sorrindo* Não. É bem estranho. É estranho porque tem mais gente em casa. 


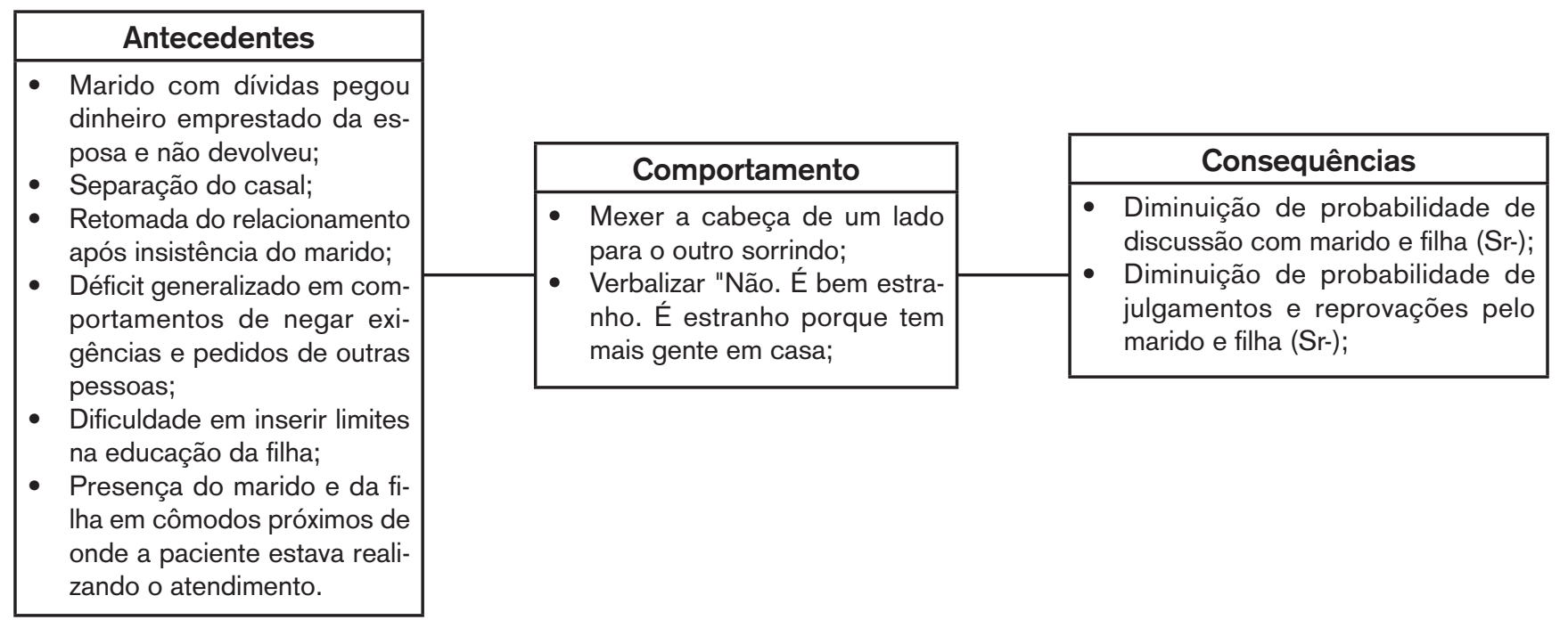

Figura 1. Análise funcional da paciente J, com base no relato transcrito do primeiro atendimento.

Neste trecho, a paciente emite o operante verbal tato "É Estranho" quatro vezes, e o operante verbal "É estranho porque tem mais gente em casa" uma vez. No caso da paciente, esse tato teve função de descrever ao acadêmico-pesquisador uma contingência aversiva em vigor, a saber, a proximidade de familiares no atendimento. Santos, Santos e Marchezini-Cunha (2012a) referem que o operante verbal tato, frequentemente utilizado tanto no dia-a-dia quanto em práticas clínicas, é uma resposta verbal controlada por um ou mais estímulos discriminativos específicos não verbais. É ainda uma fonte de informações para a identificação de contingências, ampliando o contato do clínico (ouvinte) com o paciente (falante).

Identifica-se também que a postura do terapeuta frente ao operante verbal tato da paciente foi a de uma agência de controle não punitiva, pois este não reagiu punitivamente à resposta da paciente, em outras palavras, não insistiu que ela verbalizasse o que a estava estimulando aversivamente, pois poderia ser prejudicial, visto que sua queixa também girava em torno da relação com o marido e com a filha. Medeiros (2002), Skinner (2003), Vandenberghe e Pereira (2005) estabelecem a psicoterapia como uma agência controladora na qual a postura do terapeuta deve constituir uma audiência não punitiva.
A audiência não punitiva, por parte do terapeuta, pode desenvolver a ocorrência de episódios íntimos de vulnerabilidade interpessoal na terapia, nas quais o indivíduo permite a possibilidade de crítica ou rejeição. Desse modo, pode-se observar que na psicoterapia individual online, em um contexto no qual as dificuldades da paciente eram possivelmente causadas pela família, a presença desta pode se estabelecer como uma audiência punitiva. Sendo assim, nas condições observadas, a afirmação de Pieta et al. (2015) de que a psicoterapia online pode promover sentimentos de anonimato, privacidade e segurança não se confirmou. Os horários de atendimento e o local escolhido pela participante para a realização da terapia, não possibilitaram o isolamento necessário para a condução da terapia.

Outro aspecto que se deve atentar são as considerações éticas quanto a confidencialidade. Não se pode afirmar que haja maior risco de quebra de confidencialidade na modalidade online e que a forma tradicional é mais segura, entretanto não se pode negar os riscos que envolvem esta modalidade de atendimento. De modo a minimizar as chances de quebra de confidencialidade, deve sempre utilizar sistemas operacionais atualizados e originais, antivírus eficiente e atualizado e firewall ativo (Rodrigues \& Tavares, 2016). Sobre a presença 
de outras pessoas no recinto, o terapeuta verificou a possibilidade da paciente conversar com os familiares e solicitar-lhes que buscassem realizar alguma atividade fora do recinto, a qual consentiu, porém não houve resultado. Uma das hipóteses foi referente ao baixo repertório de habilidades sociais decorrente de um possível histórico de punição e, consequentemente, respostas de fuga e esquiva de conflito familiar.

Durante os atendimentos, como relatado, ocorreram diversos travamentos e quedas de conexão. Abaixo, será apresentado um trecho do atendimento no qual esses eventos ocorreram:

J: E essa semana sabe, assim... Ah, eu pensei até em fazer maldade para mim, sabe? ${ }^{*}$ choro, voz amarrada, mão passa sobre o nariz ${ }^{\star}$ Só que dai eu pensei nela, sabe? Ai eu penso quem que vai cuidar da minha filha, sabe? Penso que eu queria que ela saísse daqui. Desculpa ${ }^{*}$ choro, voz amarrada, funga, 8 " de silêncio*

T: Não, tudo bem * silêncio $5^{\prime *}$. Ahn... ${ }^{*}$ conexão trava* Alô? alo? J? está me escutando? *conexão volta após 15 "*

J: Oi, pode falar.

T: Pensei que tinha caído. Então tu me disse agora que tu... às vezes tu pensa que tu queria que a tua filha saísse daí?

J: Não, não, é que eu pensei... ah tu sabe o que eu pensei, sabe? Contra mim, mas ai eu penso, quem que vai cuidar dela, sabe? se eu não tiver aqui. ${ }^{*}$ choro, voz amarrada*

T: Certo. O quê que tu sente em relatar isso?

$\mathrm{J}$ : Eu tenho que pedir perdão a Deus por que eu penso essas coisas, sabe? ${ }^{*}$ somente testa visível T: * silêncio, 12 " ${ }^{\star}$ o quê que tu sente ao falar isso agora?

$\mathrm{J}:$ Ahn?

T: O quê que tu sente ao falar isso?

J: Dá pra ouvir? *aumento repentino do som ${ }^{\star}$

T: Bota um pouquinho mais longe ${ }^{\star}$ chamada encerrada; inicia uma nova chamada, retorno após 19 "^ $\mathrm{Oi}$

J: Oi

T: Caiu a conexão, né? * conexão cai novamente no tempo 15'56"; A mão vai a face; inspira e expira; reinicia a ligação e a chamada no tempo 16 '25" (29 segundos) ${ }^{\star}$

\section{J: Pronto. ${ }^{\star}$ aumento repentino do som ${ }^{\star}$}

T: Pronto. Caiu a conexão novamente. Tu acabou de me relatar essa situação né? Consegue me descrever aquilo que tas sentindo? Agora, no momento? ${ }^{*}$ conexão trava; chama de vídeo se torna só áudio, 35 segundos depois a paciente responde*

No trecho acima se pode perceber uma supressão no atendimento em um momento crítico, quando a paciente relatou ideações de "fazer maldade" (sic) para si mesma. Santos, Santos e Marchezini-Cunha (2012a) referem que em um episódio verbal o ouvinte, além de atuar como estímulo discriminativo ( $\mathrm{Sd}$ ), atua como aquele que libera consequências para as verbalizações (Rv) do falante. Medeiros (2002) citando Skinner (1953/1994) afirma que a punição do comportamento verbal pode suprimí-lo, representando um obstáculo ao tratamento, pois priva o terapeuta de informações essenciais sobre o paciente. Do mesmo modo, pode-se verificar a ocorrência da extinção operante, pois, afirma Skinner (2003), a extinção operante ocorre quando a resposta não é reforçada. Brandão (1999) ainda apresenta que, em termos de tempo e espaço, quão mais próximo o reforço estiver da resposta, melhor e maior será seu efeito ou probabilidade de aumentar a frequência. A perda de contato da paciente com o terapeuta pode se caracterizar como punição negativa, pois a mesma perde contato com um reforçador.

Esse evento punitivo acaba por suprimir o episódio emocional que estava ocorrendo no momento. De fato, o primeiro efeito da punição é a supressão imediata do responder, que ocorre devido a eliciação incondicional de respostas emocionais, sendo estas incompatíveis com a resposta punida, mas por mais que os efeitos supressivos sejam transitórios (Mayer, 2014), todo o contexto da presença de familiares no ambiente pode dificultar a retomada do relato.

Outro aspecto observado foi o comportamento aberto do terapeuta perante a queda de conexão, o qual levava a mão à face, inspirava e expirava e fechava os olhos. No caso analisado, dificuldades tecnológicas podem configurar-se em contingências aversivas para o terapeuta não treinado em atendimentos onlines. Segundo Banaco (1993), deve- 
se lembrar que o terapeuta, assim como o paciente, apresenta comportamentos encobertos perante o atendimento, e que este deve estar atento aos eventos encobertamente sentidos, já que podem se traduzir em comportamentos abertos que comprometam o vínculo terapêutico.

Não obstante, o terapeuta deve estar atento aos seus comportamentos abertos durante os atendimentos online, pois caso aconteça uma retomada de conexão no momento em que o terapeuta estiver bufando, revirando os olhos, cobrindo o rosto entre outros; estima-se que esse possa se tornar um evento punitivo e influenciar de modo negativo a psicoterapia. Ressalta-se que, até o momento em que foi finalizado este artigo, a paciente compareceu a um atendimento presencial. Embora não se possa afirmar com rigor, a solicitação do atendimento presencial ainda pode ser um indício do estabelecimento de vínculo na relação terapêutica. A paciente procurou o pesquisador-acadêmico para continuar o atendimento apesar das situações experimentadas nos atendimentos online. Neste atendimento, a paciente pôde verbalizar a queixa que estava relacionada ao seu marido, além de terem sido abordados temas referentes ao trabalho e à forma como ela se comporta com a filha. Um ambiente confortável e acolhedor para que a paciente possa falar o que quiser e como quiser, além de um ambiente onde o terapeuta seja um reforçador, podem vir a estabelecer um bom vínculo terapêutico (Alves \& Isidro-Marinho, 2010). No caso em questão, a não insistência do terapeuta para a verbalização de situações constrangedoras pode ter contribuído, inicialmente, para o estabelecimento de vínculo. Ainda, além do estabelecimento de vínculo, e por todo o contexto de conflitos familiares descrito até então pela paciente, a solicitação para atendimentos presenciais poderia ser indício de outro processo em vigor, como a fuga do ambiente doméstico.

\section{Considerações Finais}

No âmbito desta pesquisa, o qual buscou avaliar o estabelecimento do vínculo terapêutico online, na abordagem da Análise Clínica do Comportamento, em pessoas que apresentam comportamentos de fuga e esquiva em situações sociais. Pelo baixo número de retorno dos participantes, optou-se por se realizar um relato de caso. Pôde-se averiguar que, nas condições apresentadas durante os atendimentos, os travamentos e quedas de conexão podem vir a interferir tanto no estabelecimento do vínculo terapêutico como no tratamento em si. Entretanto, na presença de outras pessoas no mesmo recinto, a premissa de que a psicoterapia online pode garantir o anonimato e privacidade não foi confirmada, de modo que a paciente solicitou atendimentos presenciais.

Este relato também indica a possibilidade do uso de elementos fora do controle do terapeuta que possam servir de fuga e esquiva do participante. $\mathrm{O}$ controle da participante sobre o que é capturado pela câmera pode evitar a apresentação de expressões faciais que ainda não se sente confortável em mostrar, utilizar momentos de falha da conexão para revelar conteúdo mais sensível. Ambos acontecimentos foram registrados nos atendimentos e podem servir como estratégias para diminuir a probabilidade de punição. É possível que, nesse caso, tenha servido como uma contingência pouco punitiva para o desenvolvimento de repertório para revelar conteúdos sensíveis, que posteriormente se apresentaram em contato presencial.

Outros relatos de caso sobre atendimento online para casos de pessoas com ansiedade social se fazem necessários para identificar padrões de comportamentos em situação online, bem como a utilização de recursos (ou falhas) tecnológicas como ferramenta de fuga ou esquiva. Contudo, com os dados obtidos, salienta-se a necessidade de que tanto terapeuta como paciente apresentem uma boa conexão com a internet e meios seguros de comunicação, bem como que ambos se comprometam com a confidencialidade das sessões. Há carência de dados para afirmar se as faltas se deram devido às dificuldades tecnológicas, presença de familiares ou devido ao possível quadro de ansiedade social da paciente, o qual não se pôde verificar com acurácia. Do mesmo modo, não se pode afirmar com rigor o quão punitivo, ou se mesmo foi punitivo, os travamentos e quedas de conexão para a paciente, bem como os comportamentos do terapeuta nesses episódios podem influenciar o vínculo terapêutico.

Ainda neste relato de caso, houve dificuldades no recrutamento de sujeitos com características es- 
pecíficas que contemplassem os objetivos do projeto, porém houve aceitação dos sujeitos recrutados em realizar a psicoterapia de forma online. Para futuras pesquisas nesta área, recomenda-se utilizar uma amostra mais abrangente, que independa de um diagnóstico específico, mas sim ampliar este leque. Do mesmo modo, para superar as limitações encontradas durante os atendimentos, aconselhase estabelecer critérios de seleção referente a conexão com a internet, qualidade dos equipamentos a serem utilizados por ambos e a presença de outros indivíduos no recinto.

\section{Referências}

Alves, N. N. F. \& Isidro-Marinho, G (2010). Relação terapêutica sob a perspectiva AnalíticoComportamental. In: De-Farias, A. M. C.R. et al (Coord.). Análise comportamental clínica: aspectos teóricos e estudos de caso (pp. 66-94). Porto Alegre: Artmed.

Banaco, R. A (1993). O impacto do atendimento sobre a pessoa do terapeuta. Temas psicologia, 1(2), 71-79. Recuperado em 05 de novembro de 2017, de http://pepsic.bvsalud.org/scielo. php? script=sci_arttext\&pid=S1413-389X1993 000200010\&lng=pt\&nrm=iso

Barros, R. da S (2003). Uma introdução ao comportamento verbal. Revista brasileira de terapia comportamental e cognitiva, 5(1), 73-82, Recuperado em 19 de outubro de 2018, de http:// pepsic.bvsalud.org/scielo.php?script $=\mathrm{sci}$ arttext\&pid=S1517-55452003000100008\&lng= pt\&nrm=iso

Baum, W. M (2006). Compreender o behaviorismo: comportamento, cultura e evolução ( $2^{\mathrm{a}}$ ed.). Porto Alegre: Artmed.

Brandão, Maria Zilah da Silva (1999). Terapia comportamental e análise funcional da relação terapêutica: estratégias clínicas para lidar com comportamento de esquiva. Revista Brasileira de Terapia Comportamental e Cognitiva, 1(2), 179-187. Recuperado em 19 de outubro de 2018, de http://pepsic.bvsalud. org/scielo.php?script=sci_arttext\&pid=S151755451999000200007\&lng=pt\&tlng=pt.

Colombini, F. A. \& Pergher, N. K (2009). Decisões Clínicas na Terapia Analítico-Comportamental.
ACTA Comportamentalia. Guadalajara, 17(2), 235-253, Recuperado em 06 de novembro de 2017, de http://pepsic.bvsalud.org/ scielo.php?script $=$ sci_arttext\&pid $=$ S0188$81452009000200006 \& \operatorname{lng}=$ pt\&tlng $=$ pt.

Conselho Federal de Psicologia (2012), Regulamenta os serviços psicológicos realizados por meios tecnológicos de comunicação a distância, $o$ atendimento psicoterapêutico em caráter experimental e revoga a Resolução CFP N. ${ }^{\circ}$ 12/2005, Resolução CFP No 011/2012. Brasília: DF: Humberto Cota Verona.

Conselho Federal de Psicologia (2018), Regulamenta a prestação de serviços psicológicos realizados por meios de tecnologias da informação e da comunicação e revoga a Resolução CFP N. ${ }^{\circ}$ 11/2012, Resolução CFP No 011/2018. Brasília: DF: Rogério Giannini.

Donnamaria, Carla Pontes, \& Terzis, Antonios. (2011). Experimentando o dispositivo terapêutico de grupo via internet: primeiras considerações de manejo e desafios éticos. Revista da SPAGESP, 12(2), 17-26. Recuperado em 19 de outubro de 2018, de http://pepsic.bvsalud. org/scielo.php?script=sci_arttext\&pid=S167729702011000200003\&lng $=$ pt\&tlng $=$ pt.

Fugioka, R. O. \& de-Farias, Ana Karina C. R. (2010) Fuga e esquiva em um caso de ansiedade. In: de-Farias, Ana Karina C. R. (Coord.) e colaboradores. Análise comportamental clínica: aspectos teóricos e estudos de caso (pp. 263-272). Porto Alegre: Artmed.

Instituto Brasileiro de Geografia e Estatística, IBGE (2016). Acesso à internet e à televisão e posse de telefone móvel celular para uso pessoal. Rio de Janeiro: IBGE, 2016. Recuperado em 16 de março de 2018, de http://biblioteca.ibge.gov.br/ visualizacao/livros/liv99054.pdf

Marot, Rodrigo Sá Vicente, \& Ferreira, Maria Cristina. (2008). Atitudes sobre a aprovação da psicoterapia online na perspectiva da teoria da ação racional. Interamerican Journal of Psychology, 42(2), 317-324. Recuperado em 19 de outubro de 2018, de http://pepsic.bvsalud. org/scielo.php?script=sci_arttext\&pid=S003496902008000200013\&lng=pt\&tlng=pt.

Mayer, Paulo César Morales (2014). Simetria e assimetria entre reforçamento e punição (Tese 
de doutorado, Universidade Federal do Pará, Belém, Brazil). Recuperado em 30 de março de 2020, de https://www.researchgate.net/ profile/Marcus_Neto/publication/336601980_ SIMETRIA_E_ASSIMETRIA_ENTRE_ REFORCAMEN TO_E_P UNICAO/ links/5da7d0214585159bc3d44c81/SIMETRIAE-ASSIMETRIA-ENTRE-REFORCAMENTOE-PUNICAO.pdf.

Medeiros, Carlos Augusto de. (2002). Comportamento verbal na terapia analítico comportamental. Revista Brasileira de Terapia Comportamental e Cognitiva, 4(2), 105-118. Recuperado em 19 de outubro de 2018, de http://pepsic.bvsalud. org/scielo.php?script $=$ sci_arttext\&pid=S1517$55452002000200004 \& \operatorname{lng}=$ pt\&tlng=pt.

Melo, A. F (2016). A inclusão digital na escola para a erradicação do analfabetismo tecnológico. $e$ -Mosaicos - Revista Multidisciplinar de Ensino, Pesquisa, Extensão e Cultura do Instituto de Aplicação Fernando Rodrigues da Silveira. 5 (10). Recuperado em 5 de novembro de 2017 de <www.e-publicacoes.uerj.br/index.php/emosaicos/article/view/26618>

Meyer, S. B., Oshiro, C., Donadone, J. C., Mayer, R. C. F., \& Starling, R. (2008). Subsídios da obra "Comportamento Verbal" de B. F. Skinner para a terapia analítico-comportamental. Revista Brasileira de Terapia Comportamental e Cognitiva, 10(1), 105-118. https://doi. org/10.31505/rbtcc.v10i1.209

Moreira, M. B. \& Hanna, E. S (2012). Linguagem. In: Hubner, M. M. C. \& Moreira, M. B (Coord.). Temas clássicos da Psicologia sob a ótica da análise do comportamento (pp. 100-115). Rio de Janeiro: Guanabara Koogan.

Peron, Francielly; Lopes Lubi, A. P; (2012). Instâncias da relação terapêutica medidas a partir de um instrumento de categorização Acta Comportamentalia: Revista Latina de Análisis de Comportamiento, 20(1), 2012, 109-123. Recuperado em 17 de março de 2020, de https:// www.redalyc.org/pdf/2745/274523556008.pdf.

Pieta, M. A. M., Siegmund, G., Gomes, W. B. \& Gauer, G. (2015). Desenvolvimento de protocolos para acompanhamento de psicoterapia pela Internet. Contextos Clínicos, 8(2) 128140. Recuperado em 16 de março de 2018, de
$<$ http://revistas.unisinos.br/index.php/contextosclinicos/article/view/ctc.2015.82.02.

Pieta, Maria Adélia Minghelli, \& Gomes, William B. (2014). Psicoterapia pela Internet: viável ou inviável?. Psicologia: Ciência e Profissão, 34(1), 18 31. Recuperado em 03 de novembro de 2017, de http://www.scielo.br/scielo.php?script=sci_artt ext\&pid=S1414-98932014000100003 https:// dx.doi.org/10.1590/S1414-98932014000100003

Pinto, Elza Rocha. (2002). As modalidades do atendimento psicológico on-line. Temas em Psicologia, 10(2), 168-177. Recuperado em 19 de outubro de 2018, de http://pepsic.bvsalud. org/scielo.php?script=sci_arttext\&pid=S1413389X2002000200007\&lng $=$ pt\&tlng $=$ pt.

Prado, Oliver Zancul, \& Meyer, Sonia Beatriz. (2004). Relação terapêutica: a perspectiva comportamental, evidências e o inventário de aliança de trabalho (WAI). Revista Brasileira de Terapia Comportamental e Cognitiva, 6(2), 201-209. Recuperado em 19 de outubro de 2018, de http://pepsic.bvsalud.org/ scielo.php?script $=$ sci_arttext $\&$ pid $=S 1517$ $55452004000200006 \& \operatorname{lng}=$ pt\&tlng=pt.

Rico, V. V., Golfeto, R. \& Hamasaki, E. I. de M (2012). Sentimentos In: Hubner, M. M. C. \& Moreira, M. B (Coord.). Temas clássicos da Psicologia sob a ótica da análise do comportamento (pp. 88-99). Rio de Janeiro: Guanabara Koogan.

Rodrigues, C. G. \& Tavares, M. de A(2016). Psicoterapia online: demanda crescente e sugestões para regulamentação. Psicologia em estudo, 21(4), 735-744. Recuperado em 16 de março de 2018, de http://periodicos.uem.br/ojs/index. php/PsicolEstud/article/view/29658/pdf.

Santos, G. M. dos, Santos, M. R. M. \& MarcheziniCunha, V. (2012a). Operantes Verbais. In: Borges, N. B. \& Cassas, F. A (Coord.). Clínica Analítico-comportamental: Aspectos teóricos e práticos (pp. 64-76). Porto Alegre: Artmed.

Santos, G. M. dos, Santos, M. R. M., MarcheziniCunha, V. (2012b). A escuta cautelosa nos encontros iniciais: a importância do clínico analítico-comportamental ficar sob controle das nuances do comportamento verbal. In In: Borges, N. B. \& Cassas, F. A (Coord.). Clínica Analítico-comportamental: Aspectos teóricos e práticos (pp. 138-146). Porto Alegre: Artmed. 
Siegmund, Gerson, Nonohay, Roberto Guedes de, \& Gauer, Gustavo. (2016). Ensaio de usabilidade de uma intervenção psicoeducacional computadorizada sobre transtorno obsessivocompulsivo. Temas em Psicologia, 24(1), 261276. https://dx.doi.org/10.9788/TP2016.1-18

Skinner, B. F (2003). Ciência e comportamento humano (11a ed). São Paulo: Martins Fontes.

Skinner, B. F (2006). Sobre o behaviorismo. São Paulo: Cultrix.

Vandenberghe, L. \& Pereira, M. B (2005). O papel da intimidade na relação terapêutica: uma revisão teórica à luz da análise clínica do comportamento. Psicologia: Teoria e Prática,7(1) 127-136, Recuperado em 03 de novembro de 2017, de http://www.redalyc.org/ html/1938/193817415010/. 